\title{
Crystallization-Induced 10-nm Structure Formation in P3HT/PCBM Blends
}

\author{
Peter Kohn, ${ }^{\dagger, \S}$ Zhuxia Rong, ${ }^{\dagger, \S}$ Kai H. Scherer, ${ }^{\dagger, \S}$ Alessandro Sepe ${ }^{\dagger}$ Michael
}

Sommer, ${ }^{\ddagger}$ Peter Müller-Buschbaum, ${ }^{\mathbb{I}}{ }^{\mathrm{R}}$ Richard H. Friend, ${ }^{\dagger}$ Ullrich Steiner, ${ }^{*, \dagger}$ and Sven Hüttner*,†

Cavendish Laboratory, Department of Physics, University of Cambridge, J J Thomson Avenue, Cambridge CB3 OHE, UK, Institute of Macromolecular Chemistry, University of Freiburg, Stefan-Meier-Str. 31, 79104 Freiburg, Germany, and Physik Department, Technische Universität München, James-Franck-Strasse 1, 85747 Garching, Germany

E-mail: u.steiner@phy.cam.ac.uk; sh538@cam.ac.uk

\begin{abstract}
The miscibility and aggregation of PCBM ([6,6]-phenyl C61butyric acid methyl ester) in a polymer matrix is of great importance for the development of fullerene-based organic photovoltaic cells (OPVs). In this study we have systematically investigated the loading of PCBM in regio-regular and regio-random P3HT (poly-(3-hexylthiophene-2,5-diyl). Using optical microscopy we demonstrate the partial miscibility of PCBM in thermally annealed P3HT films and relate it to the relative crystallinity of P3HT. The low polydispersity and the nearly $100 \%$

\footnotetext{
*To whom correspondence should be addressed

${ }^{\dagger}$ University of Cambridge

+University of Freiburg

ITechnische Universität München

$\S$ These authors contributed equally to this work
} 
regio-regularity of a self-synthesized P3HT allowed a detailed X-ray characterization as a function of PCBM content, revealing a superstructure of periodic amorphous and crystalline lamellar domains of fully chain extended polymer chains. PCBM dissolves in the amorphous interlamellar P3HT regions (partially index-matching the X-ray scattering contrast) up to a threshold of $\sim 30 \mathrm{wt} \%$, above which PCBM aggregates start to form. These results show that crystallization of P3HT into 10-nm-wide lamellar domains sets the main length scale in P3HT/PCBM structure formation. PCBM is displaced into the amorphous intralamellar regions, swelling the lamellar stack. This structure formation by crystallization, which is intrinsic to most semicrystalline polymers, followed by the enrichment, segregation, and crystallization of PCBM provides an interdigitated structure, which is conceptually ideal for excitonic solar cells.

\section{Introduction}

In recent years, organic photovoltaic devices (OPV) have matured into a credible alternative to established photovoltaic technologies, reaching power conversion efficiencies between $7 \%^{1}$ and $<10 \% .^{2}$ Compared to single crystalline silicon solar cells, the OPV technology however still faces many challenges, including materials synthesis, device assembly and limited life times. In comparison to the bilayer junction that is commonly employed in silicon-based solar cells, OPVs require a convoluted bulk heterojunction (BHJ) with a well defined morphology on the 10-nm length scale. The contrast in device architectures arises from differing charge separation mechanisms. While photon absorption in doped silicon leads to the formation of charge carriers that are easily separated in the device potential, photo-excitation in conjugated polymeric materials leads to strongly electrostatically bound excitons that are unable to contribute to the photocurrent. Separate charge carriers are formed only at a donor-acceptor interface of two materials with sufficient offset in their molecular orbitals, and it is therefore commonly assumed that only excitons formed within their diffusion length $(\sim 10 \mathrm{~nm})$ of such an interface contribute to the photocurrent. ${ }^{3}$ This defines morphology of the conceptually optimal BHJ consisting of a bicontinuous donor-acceptor phase morphology with an internal resolution of ca. $10 \mathrm{~nm}^{4-6}$ which let to the mostly empirical devel- 
opment of different ways for controlling the active layer morphology. ${ }^{7}$ Substantial advance was made in terms of device performance but very little progress was made in the understanding of the interplay of structure in BHJs and their electronic properties.

One of the most studied OPV-blends is the mixture of poly-(3-hexylthiophene-2,5-diyl) (P3HT) and [6,6]-phenyl C61butyric acid methyl ester (PCBM), which are the subject of this article. A range of methods was used to investigate the phase separation of P3HT-fullerene solar cells, including imaging methods, ${ }^{8,9} \mathrm{X}$-ray scattering ${ }^{10-16}$ and neutron scattering. ${ }^{17-19}$ The vertical phase separation was studied by Ellipsometry, ${ }^{20}$ SIMS $^{21}$ and XPS. ${ }^{22}$

The optimization of OPV device performance typically involves the empirical adjustment of the PCBM/polymer ratio ${ }^{23}$ and the variatoion of processing conditions. These are often nonequilibrium thermodynamic states that are frozen-in during device processing. Efficient devices require pure, crystalline PCBM and $\mathrm{P} 3 \mathrm{HT}$ as well as molecularly intermixed regions of amorphous P3HT and PCBM. The latter is promoted by the partial miscibility of PCBM in amorphous P3HT. ${ }^{10,12,24-27}$ The competition between P3HT crystallization and fullerene aggregation seems to play a crucial role ${ }^{13,28}$ and various experiments have been carried out to understand the influence of processing conditions ${ }^{29,30}$ and annealing procedures. ${ }^{11,14,17,20,31,32}$ The use of solvent additives often has a beneficial effect on device operation. ${ }^{33-35}$

Despite the mounting evidence of P3HT miscibility and the importance of P3HT crystallization in the structure formation process, spinodal decomposition of an acceptor-donor blend during the preparation of the photoactive layer is still an often invoked model. It is based on a quench of a binary blend from a mixed to a demixed state, leading to spontaneous (spinodal) demixing. For equal donor-acceptor volume fractions this is thought to lead to a bicontinuous spinodal morphology. ${ }^{36}$ The spinodal model has, however, a number of fundamental limitations, which questions its suitability to guide OPV manufacture. (1) Spinodal lengths are typically limited to micrometer range: $10-\mathrm{nm}$ patterns by spinodal demixing have not been reported and the required thermodynamic parameters to generate a spinodal pattern on the 10-nm length scale that are not typically found in binary macromolecular blends. (2) There is increasing evidence that some successful 
photovoltaic blends are partially miscible. ${ }^{10,15,26}$ (3) Most conjugated polymers crystallize, which may lead to an interplay of crystallization and phase separation. ${ }^{37}$ (4) Photoactive layers are typically deposited by spin-coating that may lead to quenched donor-acceptor phase morphologies far from equilibrium, which cannot be equilibrated by subsequent processing steps. The interplay of morphology and the nature of each of the separated phases is decisive for device performance. Control over crystallinity, packing, phase purity and phase connectivity is most likely required to enable long-distance charge carrier transport to the electrodes, while the correct phase dimensions are important to optimize exciton separation and charge carrier generation.

The purpose of this study is investigation of structure formation in the photovoltaic model blend P3HT/PCBM. Three methods were combined to gain insight into the thermodynamics of this semiconducting blend. P3HT/PCBM mixtures were cast in thin films and the emerging morphologies were studied by optical microscopy and also compared to polystyrene (PS)/PCBM blends. Secondly, UV-Vis spectra of temperature annealed blends were examined, and thirdly small and wide angle scattering (SAXS and WAXS) results of bulk samples were compared with grazing incidence SAXS and WAXS (GISAXS, GIWAXS) of thin films. For this study very well-defined low-molecualar weight P3HT with a low polydispersity and high regio-regularity was used. ${ }^{38}$ This P3HT arranges in a periodic superstructure separating amorphous and crystalline domains and serves as an ideal model material to study structure formation by X-ray scattering. The obtained results paint a new picture of the interplay of P3HT/PCBM phase formation and crystallization on the 10-nm length scale, which is the typical width for polymer ${ }^{39}$ and in particular P3HT crystals. ${ }^{38}$

\section{Results}

\section{P3HT/PCBM Miscibility}

In order to better understand the interplay of crystallization and structure formation in the the blend,we have investigated the demixing behavior of PCBM within a matrix in four different polymers. Two 98\% regio-regular P3HT batches (P3HT-RR1, P3HT-RR2), one regio-random P3HT 

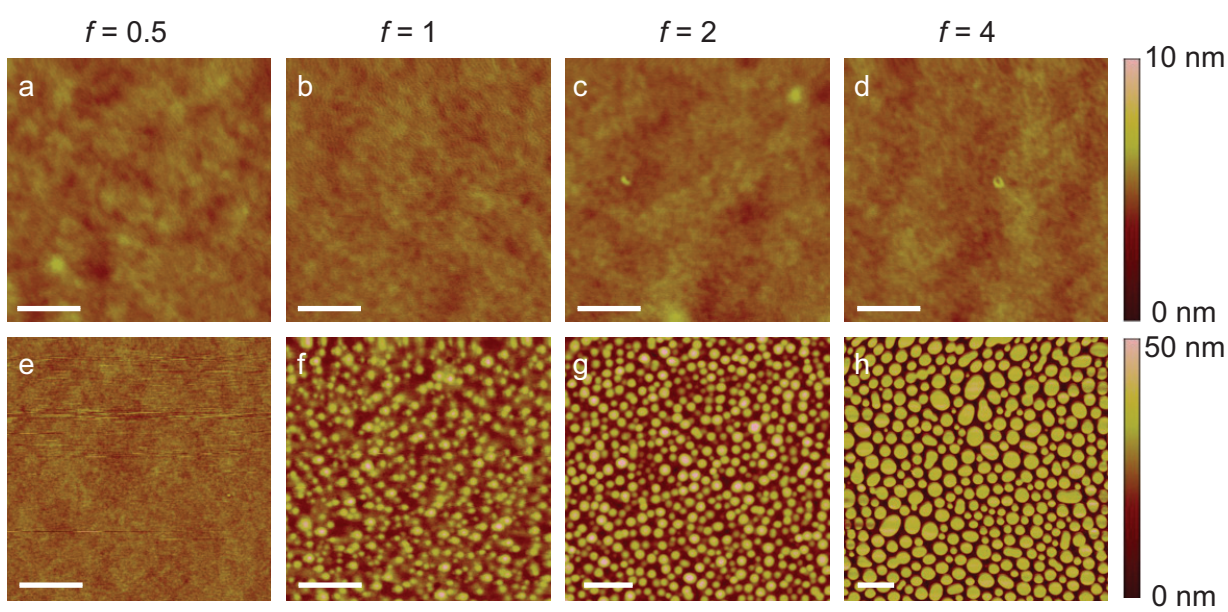

Figure 1: AFM images of (a-d) P3HT-RR1/PCBM films (scale bar: $500 \mathrm{~nm}$ ) and (e-h) PS/PCBM films (scale bar: $1 \mu \mathrm{m}$ ). The PCBM to polymer weight fraction was varied from $f=0.5$ to $f=4$.

(P3HT-RA) and amorphous polystyrene (PS) were used (see Experimental Section). P3HT-RR1 is a widely used commercial high performance P3HT with a molecular weight of around $30 \mathrm{~kg} / \mathrm{mol}$. The self-synthesized P3HT-RR2 has a molecular weight of $M_{\mathrm{n}}=11.7 \mathrm{~kg} / \mathrm{mol}$. As demonstrated previously, ${ }^{38} \mathrm{P} 3 \mathrm{HT}$ of this molecular weight forms fully chain extended crystals. The four polymers were blended with PCBM at weight ratios $f$ ranging from 0.5 to 4 , dissolved in chlorobenzene, and films were produced by spin-coating. The resulting films were approximately $100 \mathrm{~nm}$ thick. The evolving phase morphology in the four blend films was imaged by optical microscopy and atomic force microscopy (AFM).

First, as-cast films of P3HT-RR1 were investigated. In Fig. 1a-d, the as-cast films did not exhibit any optically discernible structure, irrespective of the blend mixing ratio. XPS results (not shown) show a nearly pure P3HT surface composition, in agreement with earlier results. ${ }^{22,32}$ Replacing P3HT with PS, on the other hand, reveals PCBM-rich isolated domains in a PS-rich matrix for most of the PS/PCBM composition range, a phase morphology which is similar to commonly studied macromolecular mixtures. ${ }^{36}$

The difference between these two sample series may have several reasons. The lack of structure in the as-cast P3HT/PCBM film may (1) be indicative of a better blend compatibility of the two components, (2) arise from a layered (laterally stratified) morphology of two coexisting phases, 

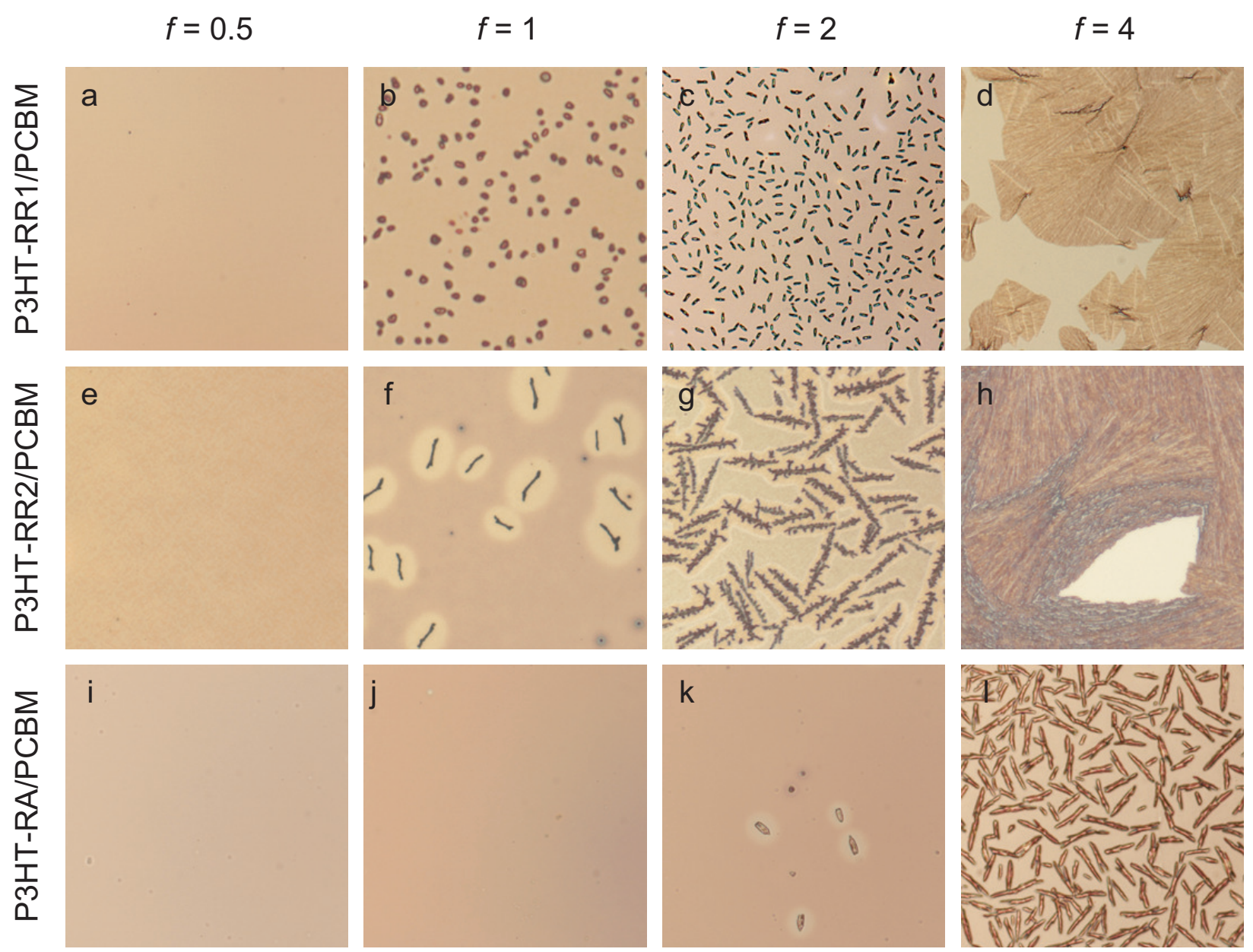

Figure 2: Optical microscopy images of (a-d) P3HT-RR1/PCBM, (e-h) P3HT-RR2/PCBM, and (i-1) P3HT-RA/PCBM films. The PCBM to polymer weight fraction was varied from $f=0.5$ to $f=4$. Image widths: $500 \times 500 \mu \mathrm{m}^{2}$.

(3) result from an arrest of phase-coarsening by sufficient rapid solidification of the film, e.g. by crystallization of one of the components.

Thin P3HT/PCBM films were further studied upon annealing at $175^{\circ} \mathrm{C}$ (Fig. 2). While the melting points of $\mathrm{P} 3 \mathrm{HT}$ and PCBM are well above $200^{\circ} \mathrm{C}$, the blend was shown to exhibit eutectic behavior with a substantial melting point depression. ${ }^{23,30}$ Fig. 2 compares blends of the three P3HT types with PCBM for four mixing ratios. Below the symmetrical $f=1$ weight fraction, the blend films remained morphologically homogeneous on the micrometer length scale. Blends incorporating the regio-regular P3HT-RR1 and P3HT-RR2 showed an irregular domain structure which is attributed to the formation of PCBM aggregates. For the very high $(f=4)$ PCBM content, the 
films dewetted and showed macroscopic crystallinity. Comparing blends containing regio-regular and regio-random P3HT show a remarkable difference. PCBM aggregates appear in the P3HTRA/PCBM blend for double the PCBM loading $(f=2)$, compared to the crystallizable polymer, where structure in the films was discernible above $f=1$. Note also that some the PCBM aggregates in Fig. 2 are elongated and exhibit branched morphologies, which is atypical for amorphous aggregates and suggests PCBM crystallization.

While a quantitative analysis of the images in Fig. 2 is difficult because of the compositiondependent softening point of the P3HT/PCBM blend, the comparison of regio-regular and regiorandom P3HT-containing blends is illuminating. The composition series of the latter is clearly indicative of partial P3HT/PCBM miscibility and it suggests that approx. two parts of PCBM per part amorphous $\mathrm{P} 3 \mathrm{HT}$ are miscible. However, a quantitative miscibility limit is difficult to deduce from these images and we have used X-ray techniques to make more accurate estimations. Roughly, the miscibility limit of PCBM in crystal-forming regio-regular P3HT is about $1 / 2$ of regio-random P3HT. With crystal volume fractions of typically 50-70\% of polycrystalline P3HT, the reduction in $\mathrm{P} 3 \mathrm{HT}$ miscibility in these materials by a factor of $\sim 2$ is in qualitative agreement with the lower volume fraction of amorphous P3HT in these blends.

Figure $2 \mathrm{f}$ and $\mathrm{k}$ show PCBM depleted areas around the PCBM crystals, which arise from the nucleation of PCBM crystals and the subsequent PCBM diffusion to these crystals. A quantitative analysis of these depletion regions by Watts show that $\sim 19$ vol\% PCBM remain mixed in P3HT within the depleted regions. ${ }^{24}$

The dependence of PCBM miscibility on P3HT crystallinity is further substantiated in Fig. 3 for a P3HT-RR1:P3HT-RA/PCBM ternary blend, where the P3HT/PCBM blend ratio was fixed to $f=1$. The continuous variation of P3HT-RR1:P3HT-RA from pure P3HT-RR1 to pure P3HT-RA shows reduction in area fraction of PCBM clusters, indicating an increase in PCBM miscibility. This is also demonstrated by comparing the UV-Vis absorbance in Fig. 3b for the P3HT mixtures with the area fraction of detected PCBM clusters in Fig. 3c, showing a qualitative correlation between overall P3HT crystallinity (as seen by the vibronic peaks above $500 \mathrm{~nm}$ ) and the relative 
a
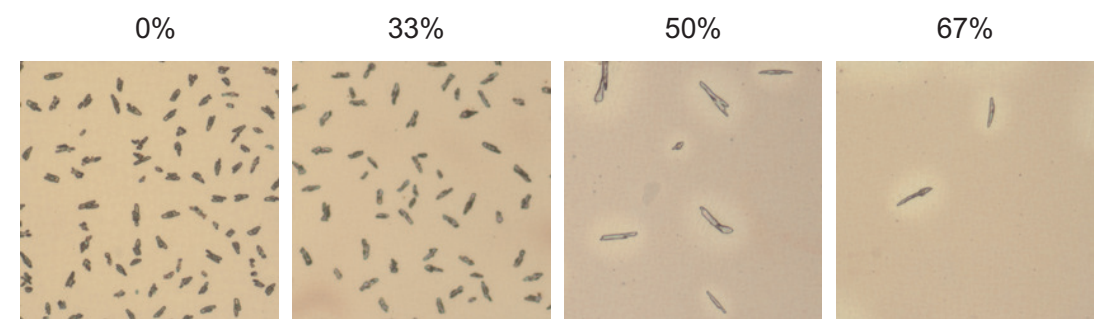

$100 \%$
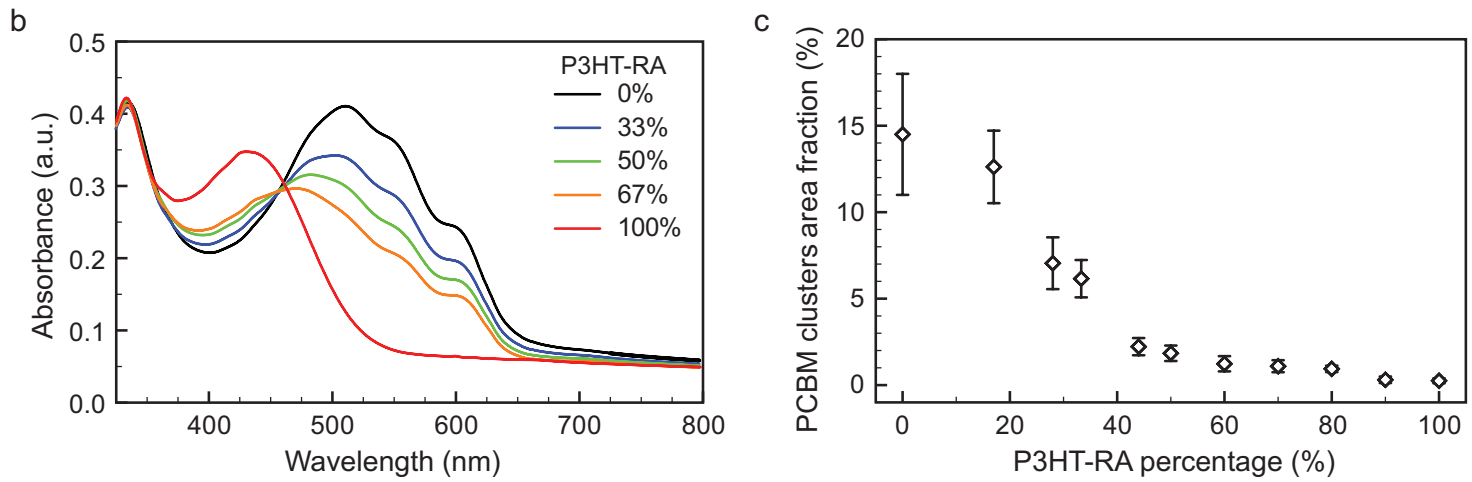

Figure 3: (a) Optical microscopy images of P3HT/PCBM films ( $f=1$, image widths: $250 \times$ $250 \mu^{2}$ ), (b) Corresponding UV-Vis spectra, and (c) Area fraction of PCBM aggregates from optical micrographs as a function of weight percentage of P3HT-RA in the P3HT-RR1/P3HT-RA mixtures. All films were annealed for $2 \mathrm{hrs}$ at $175^{\circ} \mathrm{C}$.

amount of PCBM that can be homogeneously accommodated in the P3HT/PCBM blend.

\section{Temperature-quenched P3HT crystallization}

In typical device manufacture, $\mathrm{P} 3 \mathrm{HT} / \mathrm{PCBM}$ blends are solution cast followed by annealing at temperatures below the $\mathrm{P} 3 \mathrm{HT}$ melting point. While yielding functional solar cells, this approach is likely to trap the blend far from thermodynamic equilibrium. To carry out a well defined study of the interplay of crystallization and demixing, a commonly used experimental protocol was used. After solution casting, the blend was heated to $240{ }^{\circ} \mathrm{C}$, well above the eutectic melting point of the blend. The samples were then quenched with a well-defined cooling rate to enable crystallization from a homogeneously mixed blend. P3HT-RR2 was chosen as a well-defined model system. While OPV devices typically use higher molecular weight P3HT the high regio-regularity of P3HTRR2 enable an improved resolution of the scattering experiments below. 
In preparation for the X-ray scattering experiments of the following section, the crystallization of P3HT/PCBM blends upon quenching from the amorphous phase at high temperatures was studied by UV-Vis spectroscopy, using the regio-regular P3HT-RR2. Films with PCBM weight fractions $f$ between 0 and 1 were cast onto quartz substrates. Upon heating to $240{ }^{\circ} \mathrm{C}$, the characteristic vibronic UV-Vis peak structure is lost, indicating that this temperature lies above the P3HT melting point for all samples. The spectra of as-cast films heated to $120{ }^{\circ} \mathrm{C}$ and samples quenched from $240{ }^{\circ} \mathrm{C}$ to $40{ }^{\circ} \mathrm{C}$ are shown in Fig. 4a,b. An isosbestic point was found at $\sim 400 \mathrm{~nm}$ for all samples.

To confirm the existence of an isosbestic point, the spectra were integrated in wavelengthranges in which the signal is dominated by PCBM or P3HT absorption, respectively. For this analysis it is useful to express the P3HT/PCBM mixing ratio in terms of the PCBM volume fraction $\phi=(1+\Delta \rho / f)^{-1}$, with $\Delta \rho$ the PCBM:P3HT density ratio $\left(\Delta \rho \approx 1.13\right.$ using $\rho_{\mathrm{PCBM}}=1.3 \mathrm{~g} / \mathrm{cm}^{3}$, $\rho_{\mathrm{P}_{3} \mathrm{HT}_{\text {cryst }}}=1.15 \mathrm{~g} / \mathrm{cm}^{3}$, and $\left.\rho_{\mathrm{P}_{3} \mathrm{HT}_{\text {amorph }}}=1.05 \mathrm{~g} / \mathrm{cm}^{3}\right) .{ }^{40}$ The PCBM intensity was normalized at $\phi=0.3$

$$
I_{\mathrm{PCBM}}(\phi)=0.30 \frac{\int_{\lambda_{1}}^{\lambda_{2}} d \lambda[I(\lambda, \phi)-(1-\phi) \cdot I(\lambda, 0)]}{\int_{\lambda_{1}}^{\lambda_{2}} d \lambda[I(\lambda, 0.30)-(1-0.30) \cdot I(\lambda, 0)]}
$$

for PCBM with $\lambda_{1}=260 \mathrm{~nm}$ and $\lambda_{2}=335 \mathrm{~nm}$ and

$$
I_{\mathrm{P} 3 \mathrm{HT}}(\phi)=\frac{\int_{\lambda_{1}}^{\lambda_{2}} d \lambda I(\lambda, \phi)}{\int_{\lambda_{1}}^{\lambda_{2}} d \lambda I(\lambda, 0)}
$$

for P3HT (normalized at $\phi=0$ ) with $\lambda_{1}=500 \mathrm{~nm}$ and $\lambda_{2}=625 \mathrm{~nm}$.

The fact that all data points lie on straight lines in Fig. $4 \mathrm{c}$ that intersect at $\phi=0.5$ indicates that the signals stemming from the P3HT and PCBM spectral regions are additive and proportional to their volume factions, thus leading to an isosbestic point in the UV-Vis spectra. This is a clear indication that, in terms of their spectral response, they consist of separate crystalline P3HT and amorphous P3HT/PCBM phases. Since crystalline and disordered P3HT have very different absorption properties an isosbestic point is only expected if the ratio of ordered to disordered P3HT does not change dramatically upon PCBM addition. These results are mirrored by the data for the 


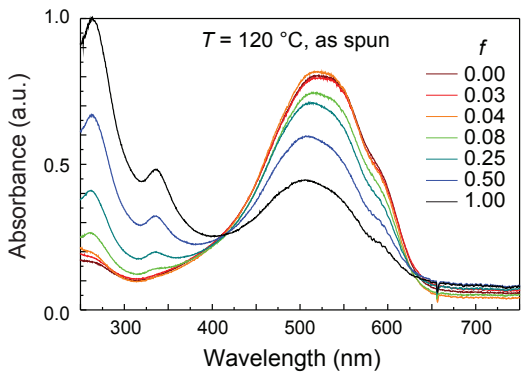

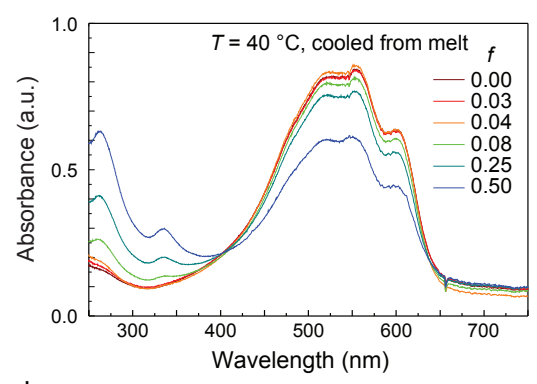

d

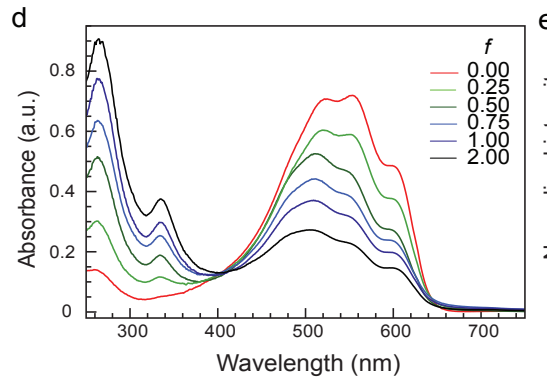

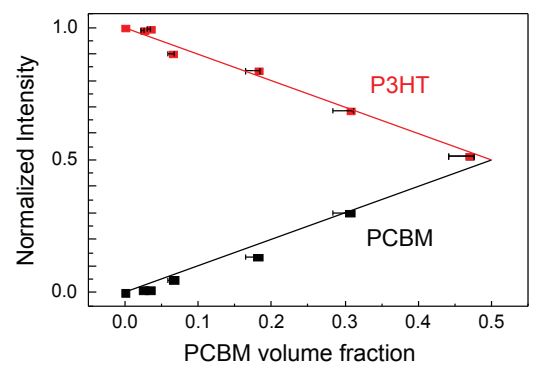

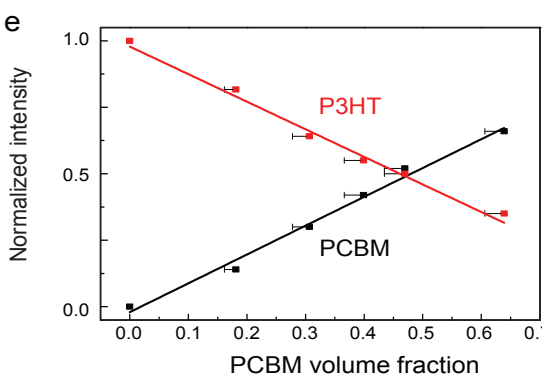

Figure 4: UV-Vis spectra of P3HT-RR2/PCBM films as a function of PCBM weight fraction $f$, (a) as spun, heated to $120{ }^{\circ} \mathrm{C}$ and (b) annealed at $240{ }^{\circ} \mathrm{C}$ followed by quenching to $40{ }^{\circ} \mathrm{C}$. (c) Integrated intensities versus PCBM volume fraction. The error bars correspond to uncertainties in $\Delta \rho$ which arise from different published values of the PCBM-density. ${ }^{40,41}$ (d) and (e) show similar data for the P3HT-RR1/PCBM blend.

\section{P3HT-RR1/PCBM blend in Fig. 4d,e.}

Further information about P3HT crystallinity can be obtained by comparing the two vibronic peaks at $555 \mathrm{~nm}$ and $610 \mathrm{~nm}$ in Fig. $4 \mathrm{~b}$ in a Spano analysis. ${ }^{42}$ The ratio of the two H-aggreagate absorbance peaks is given by $\left[\left(1-0.24 W / E_{\mathrm{p}}\right) /\left(1+0.73 W / E_{\mathrm{p}}\right)\right]^{2}$, where $E_{\mathrm{p}}=0.18 \mathrm{eV}$ is the energy of the symmetric $\mathrm{C}=\mathrm{C}$ stretch, and $W$ is the free exciton bandwidth within the crystalline phase, quantifying the crystalline order within P3HT. The ratio of the two vibronic peaks in Fig. 4b is nearly constant, corresponding to only a small increase in $W$ from $\approx 28 \mathrm{meV}$ to $\approx 32 \mathrm{meV}$ as $f$ is varied from 0 to 0.5 . This indicates that the $\mathrm{P} 3 \mathrm{HT}$ interchain order is affected only very little by PCBM addition.

These two observations are therefore further evidence that the addition of PCBM does not strongly influence P3HT crystallinity, i.e. the addition of PCBM neither substantially hinders nor enhances P3HT crystallinity although crystallisation temperatures may shift slightly. 


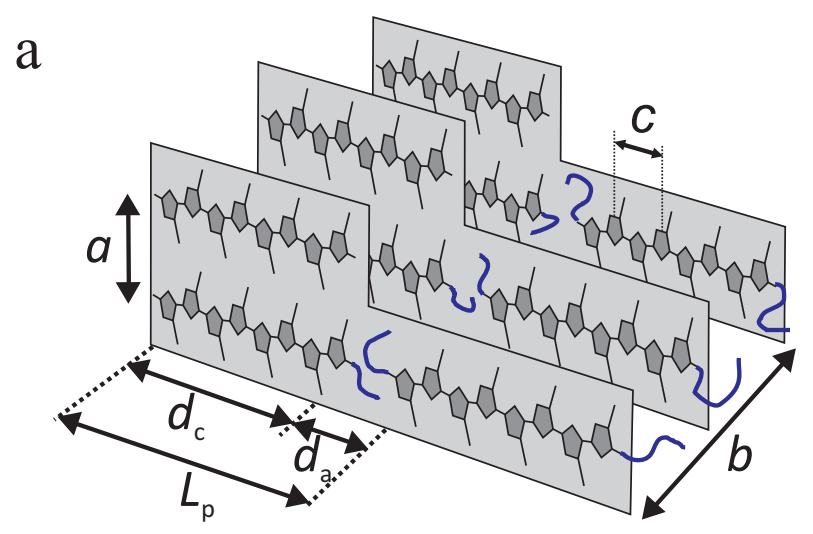

b

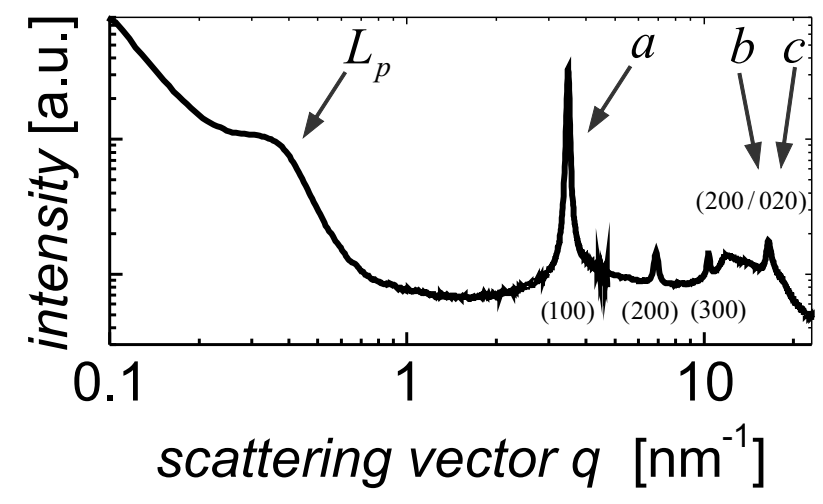

Figure 5: (a) Schematic of the semi-crystalline structure of regio-regular P3HT. $a, b$ and $c$ represent the crystal lattice constants; $d_{\mathrm{c}}$ and $d_{\mathrm{a}}$ are the thicknesses of the crystal and amorphous lamellae, respectively; $L_{\mathrm{p}}=d_{\mathrm{c}}+d_{\mathrm{a}}$ is the long period. Note that P3HT with molecular weights of 11.7 $\mathrm{kg} / \mathrm{mol}$ forms fully chain extended crystals without any chain folds. (b) Combined SAXS and WAXS scattering pattern of a pure bulk P3HT-RR2 sample. The reflections resulting from the semi-crystalline structures in (a) are indicated.

\section{WAXS and SAXS measurements of bulk P3HT/PCBM blends}

The results of partial miscibility of $\mathrm{P} 3 \mathrm{HT}$ and $\mathrm{PCBM}$ from the previous sections raises the question about the microscopic distribution and conformation of these two materials in the blend. To this end, structural analysis by wide and small angle scattering were performed using synchrotron radiation. The following investigations were all carried out on P3HT-RR2 which is highly regioregular (carrying only one coupling defect) and has a low polydispersity.

The crystal structure of P3HT is well known. ${ }^{13}$ It is schematically illustrated in Fig. 5a. Regioregular P3HT forms crystal sheets by $\pi$ - $\pi$-stacking of the thiophene rings, which stack in such a way that the alkane side chains can crystallize (mostly only for lower molecular weights). As 
commonly observed for macromolecular crystals, the material forms $\sim 10$-nm-wide crystalline regions separated by amorphous interlayers. The principal dimensions of the P3HT unit cell ( $a, b$, and c) can be resolved by WAXS, while the so-called long period $L_{\mathrm{p}}$ of the crystalline-amorphous lamellar structure gives rise to a SAXS scattering signal. The scattering contrast arises from an electron density difference of the amorphous and crystalline P3HT layers of width $d_{\mathrm{a}}$ and $d_{\mathrm{c}}$, respectively $\left(L_{\mathrm{p}}=d_{\mathrm{a}}+d_{\mathrm{c}}\right)$. A combined WAXS-SAXS spectrum of P3HT-RR2 is shown in Fig. 5b, clearly resolving all salient characteristics of the P3HT signal. P3HT-RR2 with a molecular weight of only $M_{\mathrm{n}}=11.7 \mathrm{~kg} / \mathrm{mol}$ only forms fully chain extended crystals, reducing the limitation in swelling of the amorphous domains imposed by tie-chains between crystalline domains. ${ }^{26}$

In order to monitor the PCBM distribution upon P3HT crystallization on the length scale of Fig. 5a, WAXS and SAXS measurements of blends of P3HT/PCBM with PCBM weight fractions $f$ ranging from 0 to 2 were measured. While the very low weight fractions are unimportant for device manufacture, they were included to gain an understanding of the effect of small PCBM concentrations on P3HT crystallization.

Figure 6a shows Lorentz corrected SAXS patterns of P3HT/PCBM blends for different PCBM weight fractions, recorded at room temperature after cooling from the molten state at $240{ }^{\circ} \mathrm{C}$. The peak-position of pure P3HT ( $f=0$ ) stems from a long period of $L_{\mathrm{p}}=14.8 \mathrm{~nm}$, which is close to the mean contour length of the P3HT chains of $16.3 \mathrm{~nm}$. With increasing PCBM-concentration the peak intensity decreases until it is no longer visible for $f=0.08$. The peak in Fig. 6b corresponding the $a$-spacing of P3HT remains unaltered. Therefore the disappearance of the reflection in Fig. $6 \mathrm{a}$ cannot arise from a decrease in crystallinity with increasing PCBM content, in agreement with the results from UV-Vis spectroscopy results above. It is known that the electron density of PCBM is higher compared to P3HT. Thus, the enrichment of PCBM-molecules in the amorphous P3HT lamellar layers increasingly reduces the contrast between crystalline and amorphous layers. The absence of a diffuse WAXS scattering peak in Fig. 7 indicates that no PCBM aggregates or crystals are formed at this low PCBM content, i.e. the PCBM is well dissolved in the amorphous P3HTinterlayers up to an overall PCBM concentration of at least $f \geq 0.08$. 

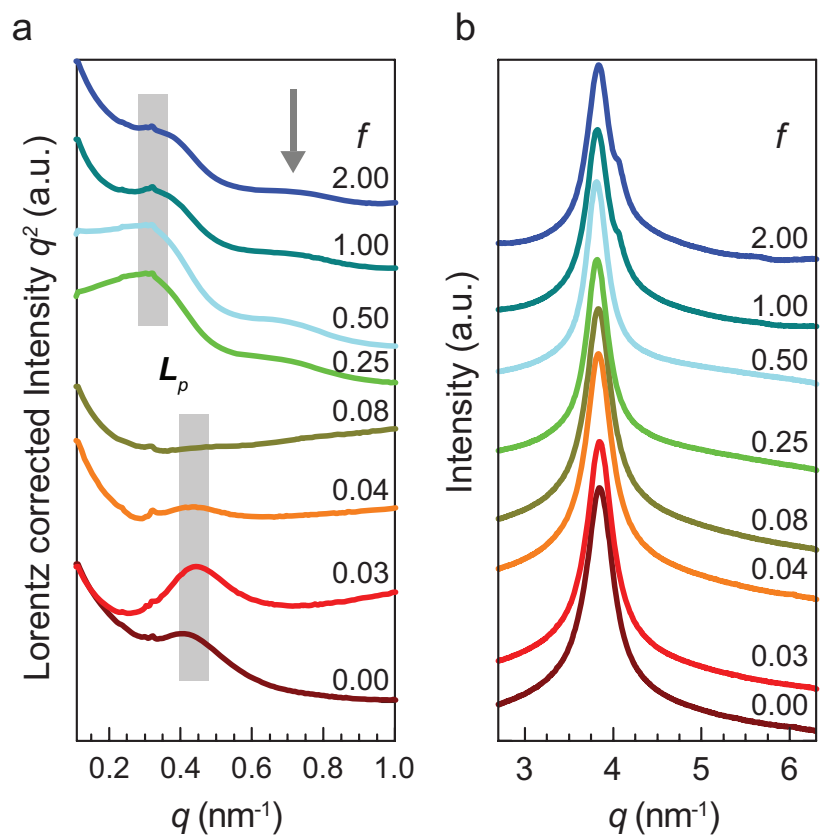

Figure 6: (a) Lorentz corrected SAXS spectra of P3HT-RR2/PCBM bulk samples. The $L_{\mathrm{p}}$-peak decreases in intensity at approximately constant $q$ with increasing PCBM loading and disappears for $f \approx 0.08$. It reappears at higher PCBM concentrations, shifted to a smaller (constant) $q$-value. The small shoulder indicated by the arrow is a second order reflection. (b) The WAXS (100)-P3HT peak of the same sample series is invariant with PCBM concentration. The numbers in (a) and (b) indicate the PCBM weight fraction $f$.

Based these data, the miscibility limits of PCBM in the amorphous P3HT interlayers can be estimated. Using the melting enthalpy of fully crystalline P3TH of $\Delta H_{\mathrm{m}}^{\infty}=37 \mathrm{~J} / \mathrm{g}^{43}$ (a value which is under dispute) and the measured melting enthalpy of P3HT-RR2 from Table 1 yields a crystallinity of $\phi_{c} \approx 65 \%$. Thus, an overall PCBM concentration of $f=0.08$ corresponds to a PCBM concentration of $23 \%$ within the amorphous interlayers in the semi-crystalline P3HT, a value where PCBM is fully miscible with amorphous P3HT (see above).

For values of $f \geq 0.25$ the peak in the SAXS-pattern in Fig. 6a reappears, shifted to smaller $q$ values. The peak position corresponding to $L_{\mathrm{p}} \approx 17-18 \mathrm{~nm}$ varied little with PCBM content. This indicates that the uptake of PCBM into the amorphous layers has "swollen" $L_{\mathrm{p}}$ by approximately $2-3 \mathrm{~nm}$. The reappearance of the reflection, i.e. the reappearance of scattering contrast between the crystalline $\mathrm{P} 3 \mathrm{HT}$ and the amorphous $\mathrm{P} 3 \mathrm{HT} / \mathrm{PCBM}$ interlayers for $f \geq 0.25$ is consistent with a further uptake of PCBM and therefore an increase in the P3HT/PCBM electron density above that of 
crystalline P3HT. The constant values of $L_{\mathrm{p}}$ for $f \geq 0.25$ (corresponding to a PCBM concentration above $70 \%$ normalized to the amorphous P3HT content in the interlamellar space) indicates that a maximum PCBM concentration in the amorphous P3HT interlayers was reached below $f=0.25$. The lower limit of $L_{\mathrm{p}}$ reappearance was further refined by the GISAXS experiments of the next section to $16.5 \mathrm{~nm}$ at $f=0.185$. Following the previous assumption of $65 \mathrm{wt} \%$ crystallinity in P3HT-RR2, a ratio of $f=0.185$ corresponds to a PCBM loading of $\sim 53 \mathrm{wt} \%$ in the amorphous P3HT interlayers, a value which is close to the critical concentration for which PCBM was found to form visible aggregates in Fig. 2.

Apart from the value of $\Delta H_{\mathrm{m}}^{\infty}=37 \mathrm{~J} / \mathrm{g}$ on which the above estimate is based, $\Delta H_{\mathrm{m}}^{\infty}=99 \mathrm{~J} / \mathrm{g}$ is sometimes given for a melting enthalpy of fully crystalline P3HT. ${ }^{44}$ This value is clearly too high since it leads to an estimate for maximal PCBM loading between $9 \%$ and $25 \%$, which is in disagreement with the results of Fig. 2 i-l. Similar or slightly lower values have been found using scanning transmission X-ray microscopy techniques. (10-20 wt\%) ${ }^{10,27}$ The difference possibly originates from the fully chain extended P3HT chains used in our study, compared to the typically used higher molecular weight P3HT, where tie chains between the crystalline lamellae my restrict the PCBM uptake. ${ }^{26}$

The WAXS-patterns in Fig. 7 for $f \geq 0.25$ is also changed compared to the spectra with low PCBM loading. For $f=0.25$ and $f=0.50$ a diffuse scattering signal in the $12-15 \mathrm{~nm}^{-1}$ and 19.5-21.5 $\mathrm{nm}^{-1} q$-range appeared, indicating the onset of PCBM aggregation. For the highest two concentrations $f=1.00$ and $f=2.00$ the signal in this $q$-range exhibits crystalline PCBM Braggreflections. Since $L_{\mathrm{p}}$ does not vary in the $0.25-2 f$-range, it is evident that a large fraction of the PCBM is no longer accommodated in the amorphous parts of the crystalline-amorphous layered structure, but has segregated out. This raises the question where PCBM aggregation and/or crystallization takes place. The invariance in $L_{\mathrm{p}}$ in the high $f$-range excludes processes at this length scale. Possible locations of longer length-scale PCBM aggregation are the domain boundaries of crystalline stacks, the film surfaces, and/or segregated-out PCBM aggregates.

The conclusion of this section is that P3HT crystallization expels PCBM into the amorphous 


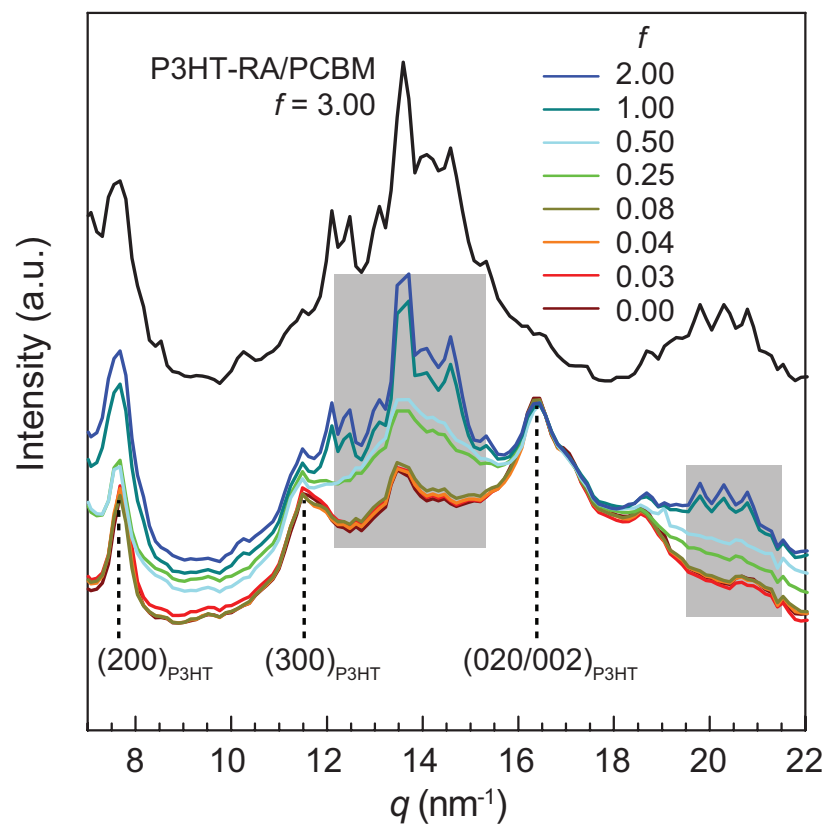

Figure 7: WAXS patterns normalized to the (020/002) reflection intensity of P3HT-RR2/PCBM bulk samples. The spectra are invariant for the lowest PCBM concentrations. At higher concentrations additional broad maxima (indicated by the grey rectangles) corresponding to PCBM aggregation become clearly visible. For the highest PCBM concentrations Bragg-peaks in these $q$ ranges indicate the formation of PCBM crystals. The spectrum of P3HT-RA/PCBM (which lacks P3HT crystallinity) is shown for a very high PCBM concentration (black line, offset for clarity).

parts of the amorphous-crystalline interlayers, leading to a PCBM concentration of $\approx 30 \mathrm{wt} \%$ in the amorphous interlayers. Further PCBM addition does not result in a further change in the P3HT/PCBM meso-morphology but causes PCBM segregation on longer length scales that can not be probed by X-ray scattering.

\section{GIWAXS and GISAXS measurements of P3HT/PCBM films}

Because of the low scattering contrast of P3HT/PCBM blends demonstrated in the previous chapter, bulk scattering experiments are advantageous for compositions, where the blend is nearly index matched. Photovoltaic devices, on the other hand consist of thin P3HT/PCBM photoactive films. It is therefore important to verify that bulk results of the previous section apply also to thin films. GIWAXS and GISAXS experiments were therefore performed on thin P3HT/PCBM layers.

Figure 8a and b show GISAXS and GIWAXS scattering patterns, respectively. Here, we have 

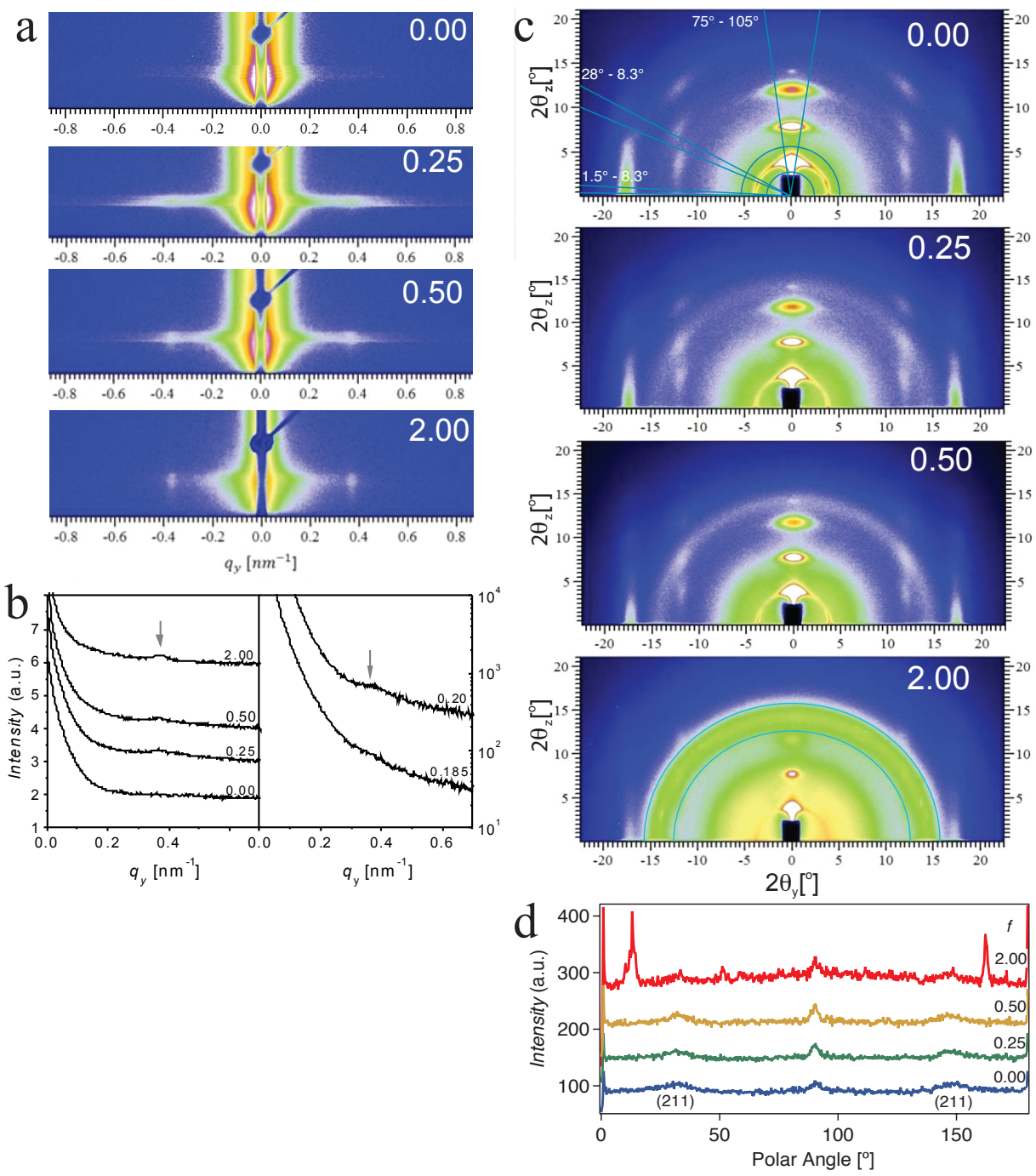

Figure 8: (a) GISAXS patterns of P3HT-RR2/PCBM film showing a lateral signal at $q \approx$ $\pm 0.4 \mathrm{~nm}^{-1}$, corresponding to the long period $L_{\mathrm{p}}$ of P3HT. (b) Corresponding 1D GISAXS intensity profiles along $q_{\mathrm{y}}$ for the different PCBM concentrations. The arrows indicate the positions of the scattering peak corresponding to $L_{\mathrm{p}}$. The curves are shifted vertically and are plotted in two separate plots as recorded on two different detectors. (c) The corresponding GIWAXS patterns (a a function of the scattering angled $\theta$ ) show the characteristic P3HT scattering signal. The lines in the $f=0$ spectrum indicate three of the sectors used for radial integration of the P3HT scattering peaks. The vertical alignment of the (h00)-reflections indicates the orientation of the P3HT $a$-axis perpendicular to the film surface. For $f=0.25$ and $f=0.50$ a diffuse PCBM-ring is visible at $q \approx 15 \mathrm{~nm}^{-1}$. For $f=2.00$, this ring exhibits several intensity spots, indicating the presence of PCBM-crystals, in agreement with the bulk WAXS spectra of Fig. 7. This is visualised in (d) showing the angular integral of the PCBM ring, delimited by the two half-circles shown in the $f=2$ spectrum. 
investigated only the high PCBM concentrations as they are relevant for device fabrication. Similar to the samples of the previous section, spin-cast films were heated above the P3HT melting point followed by slow cooling to room temperature. The GISAXS patterns show two horizontal reflections at positions which correspond to $L_{\mathrm{p}} \approx 17 \mathrm{~nm}$, i.e. values that correspond very well to those found in the bulk samples for the same PCBM concentrations, confirming similar results by Kozub et al. ${ }^{45}$ To quantify the structures, 1D intensity profiles were extracted along $q_{\mathrm{y}}$ at the $q_{\mathrm{z}}$-value of the Yoneda peak of the $\mathrm{P} 3 \mathrm{HT}^{46}$ (Fig. 8b), averaged over the $q_{\mathrm{z}}$-range where the transmission function of the polymer film has a maximum, where the scattering is dominated by the structure in the polymer film. Lorentz functions were fitted to the scattering peaks that correspond to the long period $L_{\mathrm{p}}$. These 1D spectra show the re-appearance of the long period peak at a PCBM loading as low as $f=0.185$. A comparison of the $L_{\mathrm{p}}$-values obtained from bulk and thin film measurements is shown in Fig. 9.

The horizontal positions of the GISAXS reflections show that the interfaces between crystalline P3HT and amorphous P3HT/PCBM layers are oriented perpendicular to the substrate, in agreement with the schematic drawing in Fig. 5a.

The GIWAXS spectra in Fig. 8c also show a similar signature as the bulk WAXS-patterns. The diffuse scattering rings for $f=0.25$ and $f=0.50$ are indicative of PCBM aggregation. For the highest PCBM concentration of $f=2.00$ bright spots are visible within this ring which are an indication for PCBM crystallization.

The Bragg peaks arising from P3HT in Fig. 8c were analyzed by sector integration. The P3HT lattice parameters were determined from the (100), (200), (300), (020) and (002) Bragg reflections, yielding values of $a=1.539 \mathrm{~nm}$ and $b=c=0.750 \mathrm{~nm}$. All three lattice parameters are nearly invariant upon PCBM addition. For $f=2$, the (100) and (020) peaks show a very small shift to smaller $q$-values (larger lattice spacings), by $<5 \%$ of the PCBM diameter. This confirms the wide-angle scattering results that PCBM is incorporated neither into the $\pi$ - $\pi$ stacks nor into the alkyl side-chain stacking planes. The small increase in $a$ and $c$ with $f$ presumably arises from a slightly increased crystalline disorder and a reduced measurement precision caused by signal 


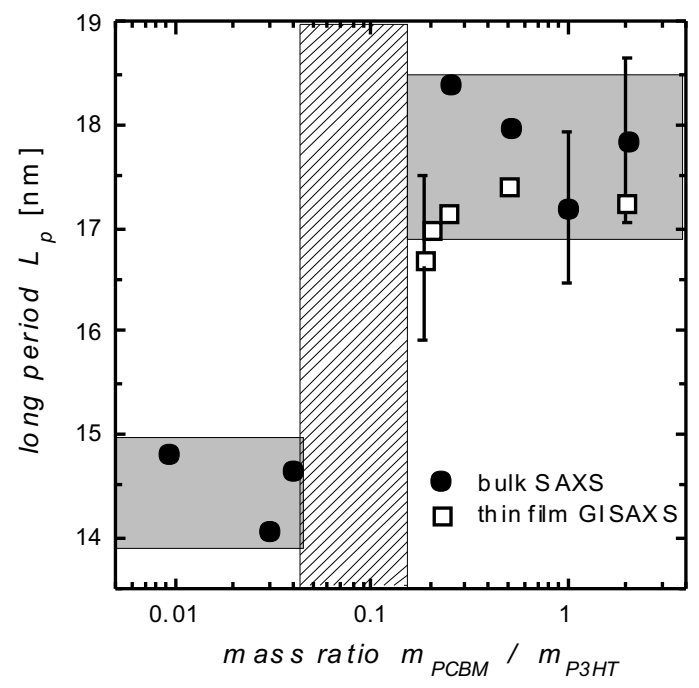

Figure 9: Comparison of $L_{\mathrm{p}}$-values obtained from the bulk SAXS (circles) and film GISAXS (squares) measurements of Fig. 7 and Fig. 8, respectively. The hatched region displays the $q$-range of insufficient scattering contrast.

superposition from PCBM scattering. Note that while the overall P3HT peak intensities decrease with increasing $f$, the peak shapes and relative peak heights remain unchanged, confirming that P3HT crystallisation is unaffected by PCBM addition.

The GISAXS and GIWAXS experiments therefore confirm that the bulk results also apply to the more relevant photovoltaic thin films. In addition these measurements confirm the predominant edge-on orientation of planarized thiophene backbones with respect to the substrate, which is not influenced by the added PCBM over the investigated concentration range. This shows that P3HT crystallization must be nucleated by one of the two interfaces (air or substrate) even for PCBM concentrations as high as $67 \mathrm{wt} \%(f=2.00)$.

\section{Discussion and Conclusion}

The combination of the experiments presented here allows a number of conclusions concerning the structure formation in P3HT/PCBM blends. Firstly, our results confirm previous reports on 
the partial miscibility of P3HT and PCBM. ${ }^{10,12,24-27}$ It is possible that this miscibility is a key requirement for materials selection. ${ }^{47}$ Macroscopic studies of P3HT/PCBM films, supported by UV-Vis and X-ray scattering experiments find a miscibility limit of PCBM in amorphous P3HT at a PCBM/P3HT weight fraction of around 2 (i.e. a limiting volume PCBM fraction of $\sim 60 \%$ ). The result that the miscibility limit of PCBM in regio-regular P3HT is approximately $1 / 2$ compared to its regio-random analog together with a typical crystallinity of 50-70\% is well explained by PCBM dissolution only in the amorphous P3HT regions. There seems very little difference between amorphous regio-regular or regio-random P3HT in their ability to dissolve PCBM. It is interesting to note that the limiting PCBM concentration in regio-regular P3HT is close to mixing ratio that is employed in the manufacture of photovoltaic devices. Surpassing the PCBM miscibility limit gives rise to micron-sized PCBM aggregates rather than a finely dispersed P3HT/PCBM morphology which may be unfavorable for photovoltaic device operation.

Secondly, P3HT-crystallinity is not strongly affected by PCBM addition. This is confirmed by the existence of an isosbestic point in the concentration series, which is independent of sample history.

Small and wide angle X-ray scattering results of bulk samples provide information about the structure of P3HT/PCBM blends on the electronically relevant 1-10 nm length scale. All SAXS measurements reveal only one single spectral feature which is also present for neat P3HT and which does not coarsen upon annealing. This scattering signal can be robustly assigned to the P3HT long-period of the P3HT spherulitic structure. The lack of a further SAXS signal in P3HT/PCBM blends rules out the formation of a spinodal demixing morphology on the 10-nm length scale, also confirming earlier interdiffusion studies. ${ }^{15,21}$

Our scattering studies allow to partially track the distribution of PCBM within the P3HT crystal structure. The addition of low concentrations of PCBM index-matches the SAXS scattering contrast, which reappears for a higher PCBM content, concurrent with an increase in the long period by 15-20\%. Index matching in the presence of unaltered P3HT crystallinity is further qualitative evidence for miscibility and enrichment of PCBM in the semicrystalline amorphous interlayers. The 
shift in the long-period for PCBM concentrations between $f=0.08$ and $f=0.185$, the detail of which is unfortunately obscured by the index-matching of the amorphous P3HT/PCBM blend with respect to the crystalline P3HT, suggests a maximal PCBM concentration between 20 and $52 \mathrm{wt} \%$ in the amorphous P3HT interlayers. A quantitative analysis of PCBM in regio-regular P3HT is additionally hindered by the lack of quantitative knowledge of the fraction of P3HT crystallinity (i.e. the precise value of the melting enthalpy of a fully crystalline P3HT).

Note that the similarity in scattering contrast of dissolved PCBM in amorphous P3HT and crystalline $\mathrm{P} 3 \mathrm{HT}$ in the interesting composition range complicates X-rays scattering as well as electron microscopy in these systems.

Renormalized to the approximate amorphous PCBM content in semicrystalline P3HT, this increase in $L_{\mathrm{p}}$ corresponds approximately to the saturation limit of PCBM in amorphous P3HT as determined by the macroscopic demixing experiment. This explains why $L_{\mathrm{p}}$ is invariant upon further PCBM addition. The fact that all wide-angle peaks corresponding to P3HT crystallinity are invariant for any PCBM content provides further evident that P3HT crystallization is not affected by the presence of PCBM at any concentration. In the high PCBM limit, WAXS shows PCBM aggregation and crystallization for symmetric $(f=1)$ P3HT/PCBM mixtures and blends with higher PCBM content.

Grazing incidence scattering experiments of thin films are in agreement with the bulk SAXS and WAXS results. They additionally confirm the well-established edge-on orientation of P3HT on the substrate surface, which is unaffected by PCBM addition. This aligned semi-crystalline structure is often considered ideal for bulk heterojunction solar cells, namely alternating layers with the interfacial plane between those layers oriented perpendicular to the substrate plane.

The drawn conclusions allow to construct a picture of the structure formation process in this photovoltaic blend, schematically shown in Fig. 10. Structure formation in P3HT/PCBM blends is initiated by $\mathrm{P} 3 \mathrm{HT}$ crystallization, which is invariant to the presence of PCBM regarding the amorphous-crystalline superstructure, the crystallinity of P3HT and orientation. P3HT crystallization segregates PCBM into the spherulitic interlamellar amorphous layers (Fig. 10d), where it 

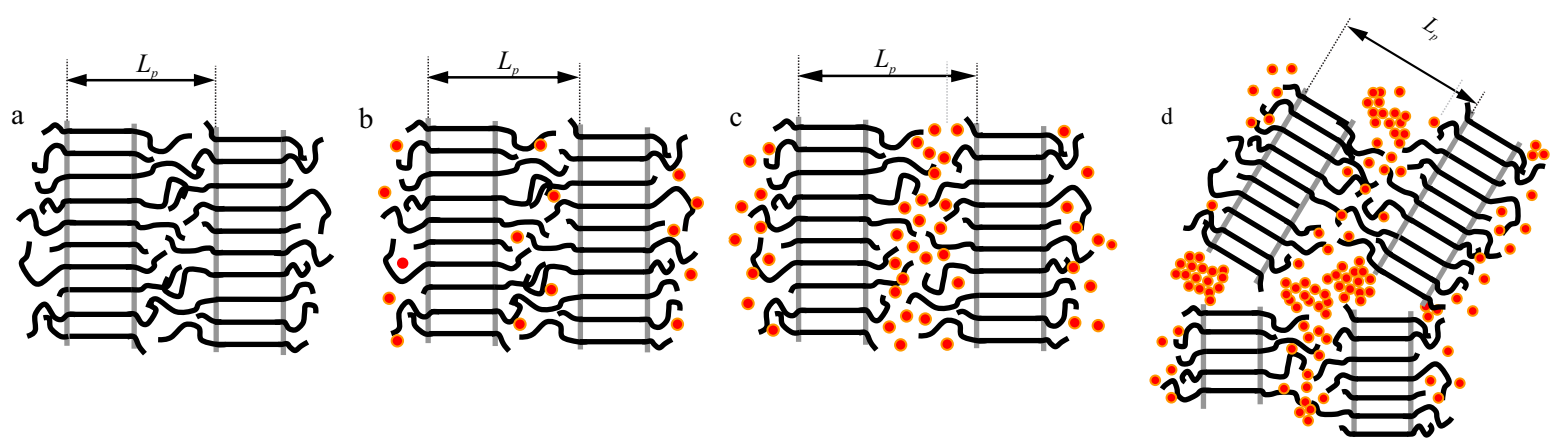

Figure 10: Sketch illustrating P3HT crystallization-induced PCBM segregation into the amorphous intra-spherulitic layers (b). At sufficiently high PCBM content in (c) this leads to the swelling of the amorphous $\sim 10 \mathrm{~nm}$ wide domains. (d) The swelling of the amorphous domains saturates. In the same time PCBM segregates out and forms aggregates.

enriches to its miscibility limit. Excess PCBM is expelled from the amorphous P3HT interlayers, presumably to the boundaries of the crystal domains (for $f<1$ ), into segregated-out PCBM aggregates (for $f>1$ ), and to the surface(s) of the of the film.

While we have not conducted a time resolved study, our results mirror the work by Wu et al. ${ }^{13}$ Annealing $\mathrm{P} 3 \mathrm{HT} / \mathrm{PCBM}$ films with $f=0.8$ and $f=1$, they find an increase in the P3HT long period and the simultaneous formation of 10 - $20 \mathrm{~nm}$-sized PCBM crystallites. Interestingly, PCMB crystal growth velocity seems to exceed the kinetics of P3HT crystal formation, implying that 10$\mathrm{nm}$ structure formation is not driven by P3HT crystallization, in contradiction to the conclusion of the present study.

The device-relevant approximately symmetric P3HT/PCBM mixture has two interesting properties: (1) it is the limiting concentration above which macroscopic PCBM segregation occurs, and (2) it is lowest concentration for which PCBM crystallization was observed.

Structure formation by crystallization of semi-crystalline polymers has intriguing benefits for photovoltaic device architecture. Because of the intrinsic 10-nm length scale of spherulitic lamellae, it provides the structural feature size that is deemed to be beneficial for exciton dissociation. It separates interconnected hole-conducting crystalline P3HT sheets from PCBM-rich interlamellar planes. While PCBM aggregation and crystallization may facilitate electron conduction, the present study is unable to discern where in the material this takes place: while the formation of 
macroscopic PCBM aggregates was observed only for PCBM fractions above $f \gtrsim 1$, SAXS data indicates that PCBM cannot be fully accommodated in the amorphous P3HT interlayers above $f \gtrsim 0.25$. In the absence of macroscopic aggregate formation, this implies the enrichment of PCBM at inter-spherulitic boundaries (Fig. 10d) in the bulk, and PCBM segregation to one or both surfaces in thin films. The present experimental techniques unfortunately do not allow to determine, whether PCBM aggregation and crystallization occurs in the interlamellar space, at the domain boundaries, or both. In the absence of direct evidence, it is likely that this gives rise to a hierarchical interconnected PCBM morphology that connects an inter-spherulitic network to the 10-nm intra-spherulitic lamellae. In combination with the edge-on orientation of the crystalline P3HT lamellar sheets, this self-assembled morphology closely approximates a conceptually beneficial bulk heterojunction. While x-ray scattering results were carried out with a very low molecular weight P3HT, recent results ${ }^{38}$ suggest that crystal morphology formation in P3HT is not strongly affected by the polymer molecular weight or the presence of defects in the chain. This is supported by preliminary device data of the films discussed here, finding comparable performance to the state-of-the-art.

In the absence of a direct correlation of the structural aspects of this study to electronic properties (work in progress), we summarize the salient features of the P3HT/PCBM blend that lead to the conceptually beneficial architecture for photoactive device layers. These include (1) the miscibility of the two components; (2) the strong asymmetry in chemical potential difference driving crystallization much more strongly in one of the components (P3HT) compared the other (PCBM); (3) the secondary aggregation and crystallization of the second component (PCBM); (4) the edgeon crystal formation of $\mathrm{P} 3 \mathrm{HT}$ together with the "ideal" orientation of the lamellae for photovoltaic devices; (5) the non-polymeric nature of PCBM, which prevents kinetic trapping of the system by the formation of entanglements.

For the structure formation in the P3HT/PCBM blend each of these 5 features are required in order for the P3HT-crystallization-driven structure formation to produce a meso-morphology that is deemed to be beneficial for bulk-heterojunction device operation. In addition to the verification 
of these statements by device studies and electronic spectroscopy, similar structural studies of other polymeric photovoltaic blends are required to generalize these findings. Furthermore, rapid solvent evaporation during spin-coating may lead to quenched P3HT/PCBM morphologies that could differ from the carefully equilibrated structures reported here.

\section{Experimental Section}

Three P3HT batches were used: P3HT-RR1: commercial P3HT Rieke Metals Sepiolid P200, molecular weight $M_{\mathrm{n}}=30 \mathrm{~kg} / \mathrm{mol}$, polydispersity index PDI $=1.7,>98 \%$ regio-regular; P3HTRR2: $M_{\mathrm{n}}=11.8 \mathrm{~kg} / \mathrm{mol}$ (measured by GPC), PDI $=1.13$, with only one coupling defect ${ }^{38}$ result- $^{-}$ ing in a polydispersity of $98 \%$ (Tab. 1); P3HT-RA: $M_{\mathrm{n}}=70 \mathrm{~kg} / \mathrm{mol}$, PDI $=3.0$, regio-random. Polystyrene (PS: $M_{\mathrm{n}}=30 \mathrm{~kg} / \mathrm{mol}, \mathrm{PDI}=1.2$, atactic) was used as a reference. The four polymers were blended with PCBM at weight fraction ranging from 0.5 to 4 (PCBM/polymer) and dissolved in chlorobenzene at a concentration of $30 \mathrm{mg} / \mathrm{ml}$. The solutions were heated at $75^{\circ} \mathrm{C}$ for 2 hrs. Silicon and quartz substrates were rinsed with deionized water, acetone and isopropyl alcohol, followed by a $10 \mathrm{~min}$ oxygen plasma etch. The solutions were spin cast at $2000 \mathrm{rpm}$ for $60 \mathrm{~s}$ and left to dry overnight in glovebox. The samples were annealed for $2 \mathrm{hrs}$ on a hotplate with a surface temperature of $175^{\circ} \mathrm{C}$. A Vecco (Bruker) Dimension 3100 system was used in the tapping mode for atomic force microscopy imaging. UV-visible absorption spectroscopy was performed using the Hewlett Packard 8453 UV-vis spectrophotometer.

Bulk samples for SAXS and WAXS measurements were prepared by drying $250 \mu \mathrm{l}$ of blend solutions from chloroform with concentrations of $20 \mathrm{mg} / \mathrm{ml}$. Samples were stored in the fume hood for two days until the complete evaporation of chloroform. The dried material was then filled into a hole $(0.8 \mathrm{~mm}$ in diameter $)$ of a small aluminum plate $(1.5 \mathrm{~mm}$ in depth) and compressed with a small stamping tool. Samples were heated into the melt and then subsequently cooled down with a constant rate of $5^{\circ} \mathrm{C} / \mathrm{min}$ to room temperature. Combined SAXS and WAXS measurements were carried out at beamline I22 at the Diamond Light Source, UK using a Pilatus 2M and a HOTWAXS 
1D gas microstrip quadrant detector at the same time.

Thin film samples for GISAXS and GIWAXS measurements were prepared by spincoating the films on precleaned silicon substrates. The measurements were performed at beamlines BW4 ${ }^{48}$ (DORIS) and P03 ${ }^{49}$ (PETRA III), HASYLAB at DESY in Hamburg, Germany. The parameters BW4 and and P03 were, respectively, as follows: The wavelength was $0.138 \mathrm{~nm}$ and $0.0957 \mathrm{~nm}$. The beam was focused by Beryllium compound refractive lenses to a size of $40 \mu \mathrm{m} \times 20 \mu \mathrm{m}$ and $22 \mu \mathrm{m} \times 11 \mu \mathrm{m}$ (horizontal $\times$ vertical) at the sample position, with an incident angle of $0.375^{\circ}$ and $0.38^{\circ}$ for GISAXS, and $0.18^{\circ}$ GIWAXS (P03). A tantalum rod with a diameter of $1.5 \mathrm{~mm}$ served as a beam stop for the intense reflected beam and the strong diffuse scattering in the incident plane. Parasitic scattering around the intense specularly reflected beam was in some cases blocked with an additional disc-like beamstop. MarCCD and Pilatus $1 \mathrm{M}$ area detectors were used for the detection of the scattered intensity. The pixel sizes were $79.1 \mu \mathrm{m} \times 79.1 \mu \mathrm{m}$ and $172 \mu \mathrm{m} \times 172 \mu \mathrm{m}$. The sample-detector distances were $2.100 \mathrm{~m}$ and $4.235 \mathrm{~m}$ for GISAXS and $0.11 \mathrm{~m}$ and $0.15 \mathrm{~m}$ for GIWAXS. The sample was moved out of the beam after each measurement to avoid beam damage.

$q_{\|}=\sqrt{q_{x}^{2}+q_{y}^{2}}$ and $q_{\mathrm{z}}$ denote the in-plane and the normal components of the scattering vector, respectively. For small incident and scattering angles, the coordinates of the $2 \mathrm{D}$ detector correspond approximately to $q_{\mathrm{y}}$ and to $q_{\mathrm{z}}$. The $q$-space calibration was performed for both beamlines by fitting the characteristic ring arising from the silver behenate scattering signal and from an angular calibration with a reference sample in GISAXS geometry.

The positions of the P3HT Bragg peaks were determined by transforming the 2D raw data into $1 \mathrm{D}$ radial scattering vectors via sector integrals $\left(1.5^{\circ}-8.3^{\circ}, 28^{\circ}-33^{\circ}\right.$ and $\left.75^{\circ}-105^{\circ}\right)$. Every $\operatorname{Bragg}$ peak was covered by an adjusted sector to minimize the background. Lorentz functions were used to fit the data. The radial $q$-values were then converted into real space distances. The $h_{100}$ spacing was calculated as the average of the (100), (200) and (300) Bragg peaks. The lattice parameters $a$, $b$ and $c$ were calculated from the (100), (200), (300), (020) and (002) Bragg reflections, assuming that the $b$ and $c$ lattice parameters are identical. Because the (020) peak is a superposition of the (020) and (002) reflexes, ${ }^{50}$ a precise determination of the (002) reflection was not possible. The 
orientation of chain stacking with respect to the substrate was investigated by processing the 2-D GIWAXS scattering data using ring integrals, indicated in Fig. 8c $(f=0)$. These integrals relate the intensity and thus frequency of chain orientation with the angle between the stacking direction and substrate, revealing an edge-on orientation of P3HT.

Table 1: Characteristics of P3HT studied further in detail.

\begin{tabular}{ccccccc}
\hline$M_{\mathrm{n}}(\mathrm{GPC})$ & PDI & $M_{\text {MALDI }}$ & $D P_{\text {MALDI }}$ & $D P_{\mathrm{NMR}}$ & $\Delta H_{\mathrm{m}}$ & $l_{\mathrm{c}}$ \\
\hline $11.8 \mathrm{~kg} / \mathrm{mol}$ & 1.13 & $6.6 \mathrm{~kg} / \mathrm{mol}$ & 40 & 43 & $24 \mathrm{~J} / \mathrm{g}$ & $16.3 \mathrm{~nm}$ \\
\hline
\end{tabular}

\section{Acknowledgement}

This work was carried out with the support of the Diamond Light Source, UK. Parts of this research were carried out at the light source DORIS III and PETRA III at DESY. DESY is a member of the Helmholtz Association (HGF). We thank J. Perlich, A. Buffet and S.V. Roth for their help during the BW4 and P03 experiment at HASYLAB, DESY. P.K. thanks T. Thurn-Albrecht for the opportunity for preliminary SAXS-measurements. Z.R. acknowledges CSC Cambridge Scholarship for funding. P.M.-B. acknowledges funding via the ISPV project of the EuroTech Green Tech Initiative. S.H., M.S. and R.H.F. acknowledge the EPSRC (grant number RG51308) as well as P.K. and U.S. acknowledge the European Commission (NMP4-SL20010-246123) for funding.

\section{References}

1. Li, G.; Zhu, R.; Yang, Y. Polymer solar cells. Nat. Phot. 2012, 6, 153-161.

2. Green, M. A.; Emery, K.; Hishikawa, Y.; Warta, W.; Dunlop, E. D. Solar cell efficiency tables (version 39). Prog. Photovolt: Res. Appl. 2012, 20, 12-20.

3. Clarke, T. M.; Durrant, J. R. Charge Photogeneration in Organic Solar Cells. Chem. Rev. 2010, 110, 6736-6767. 
4. Hoppe, H.; Sariciftci, N. Organic solar cells: An overview. J. Mater. Res. 2004, 19, 19241945.

5. Coakley, K.; McGehee, M. Conjugated polymer photovoltaic cells. J. Chem. Mater. 2004, 16, $4533-4542$.

6. Spanggard, H.; Krebs, F. A brief history of the development of organic and polymeric photovoltaics. Sol. Energy Mater. Sol. Cells 2004, 83, 125-146.

7. Nagarjuna, G.; Venkataraman, D. Strategies for Controlling the Active Layer Morphologies in OPVs. J. Pol. Sci B 2012, 50, 1045-1056.

8. van Bavel, S. S.; Sourty, E.; de With, G.; Loos, J. Three-Dimensional Nanoscale Organization of Bulk Heterojunction Polymer Solar Cells. Nano Lett. 2008, 9, 507-513.

9. Friedel, B.; Ehrler, B.; Hüttner, S.; Greenham, N. C. Enhanced Nanoscale Imaging of Polymer Blends by Temperature-Controlled Selective Dissolution. Small 2012, 2, 237-240.

10. Collins, B. A.; Gann, E.; Guignard, L.; He, X.; Mcneill, C. R.; Ade, H. Molecular Miscibility of Polymer-Fullerene Blends. J. Phys. Chem. Lett. 2010, 1, 3160-3166.

11. Verploegen, E.; Mondal, R.; Bettinger, C. J.; Sok, S.; Toney, M. F.; Bao, Z. Effect of Thermal Annealing Upon the Morphology of Polymer-Fullerene Blends. Adv. Func. Mater. 2010, 20, 3519-3529.

12. Chen, D.; Liu, F.; Wang, C.; Nakahara, A.; Russell, T. P. Bulk Heterojunction Photovoltaic Active Layers via Bilayer Interdiffusion. Nano Lett. 2011, 11, 2071-2078.

13. Wu, W.-R.; Jeng, U.-S.; Su, C.-J.; Wei, K.-H.; Su, M.-S.; Chiu, M.-Y.; Chen, C.-Y.; Su, W.-B.; Su, C.-H.; Su, A.-C. Competition between Fullerene Aggregation and Poly(3-hexylthiophene) Crystallization upon Annealing of Bulk Heterojunction Solar Cells. ACS Nano 2011, 5, 62336243. 
14. Parnell, A. J. B.; Cadby, A. J.; Mykhaylyk, O. O.; Dunbar, A. D. F.; Hopkinson, P. E.; Donald, A. M.; Jones, R. A. L. Macromolecules 2011, 44, 6503-6508.

15. Treat, N. D.; Brady, M. A.; Smith, G.; Toney, M. F.; Kramer, E. J.; Hawker, C. J.; Chabinyc, M. L. Interdiffusion of PCBM and P3HT Reveals Miscibility in a Photovoltaically Active Blend. Adv. Energy Mater. 2011, 1, 145-145.

16. Ruderer, M.; S.Guo,; Meier, R.; Chaing, H.-Y.; Körstgens, V.; Wiedersich, J.; Perlich, J.; Roth, S.; Müller-Buschbaum, P. Solvent induced morphology in polymer-based systems for organic photovolatics. Adv. Funct. Mater. 2011, 21, 3382-3391.

17. Kiel, J. W.; Eberle, A. P. R.; Mackay, M. E. Nanoparticle Agglomeration in Polymer-Based Solar Cells. Phys. Rev. Lett. 2010, 105, 168701.

18. Chen, H.; Hegde, R.; Browning, J.; Dadmun, M. D. The miscibility and depth profile of PCBM in P3HT: thermodynamic information to improve organic photovoltaics. Phys. Chem. Chem. Phys. 2012, 14, 5635-5641.

19. Ruderer, M.; Meier, R.; Porcar, L.; Cubitt, R.; Müller-Buschbaum, P. Phase separation and molecular intermixing in polymer-fullerene bulk heterojunction thin films. J. Phys. Chem. Lett. 2011, 3, 683-688.

20. Campoy-Quiles, M.; Ferenczi, T.; Agostinelli, T.; Etchegoin, P. G.; Kim, Y.; Anthopoulos, T. D.; Stavrinou, P. N.; Bradley, D. D. C.; Nelson, J. Morphology evolution via selforganization and lateral and vertical diffusion in polymer:fullerene solar cell blends. Nature Mater. 2008, 7, 158-164.

21. Chen, D.; Nakahara, A.; Wei, D.; Nordlund, D.; Russell, T. P. P3HT/PCBM Bulk Heterojunction Organic Photovoltaics: Correlating Efficiency and Morphology. Nano Lett. 2011, 11, 561-567. 
22. Vaynzof, Y.; Kabra, D.; Zhao, L.; Chua, L. L.; Steiner, U.; Friend, R. H. Surface-Directed Spinodal Decomposition in Poly[3-hexylthiophene] and C-61-Butyric Acid Methyl Ester Blends. ACS Nano 2011, 5, 329-336.

23. Müller, C.; Ferenczi, T. A. M.; Campoy-Quiles, M.; Frost, J. M.; Bradley, D. D. C.; Smith, P.; Stingelin-Stutzmann, N.; Nelson, J. Binary organic photovoltaic blends: a simple rationale for optimum compositions. Adv. Mater. 2008, 20, 3510-3515.

24. Watts, B.; Belcher, W. J.; Thomsen, L.; Ade, H.; Dastoor, P. C. A Quantitative Study of PCBM Diffusion during Annealing of P3HT: PCBM Blend Films. Macromolelcules 2009, 42, 83928397.

25. Yin, W.; Dadmun, M. A New Model for the Morphology of P3HT/PCBM Organic Photovoltaics from Small-Angle Neutron Scattering: Rivers and Streams. ACS Nano 2011, 6, 47564768 .

26. Ro, H. W.; Akgun, B.; O'Connor, B. T.; Hammond, M.; Kline, R. J.; Snyder, C. R.; Satija, S. K.; Ayzner, A. L.; Toney, M. F.; Soles, C. L. et al. Poly(3-hexylthiophene) and [6,6]-Phenyl-C61-butyric Acid Methyl Ester Mixing in Organic Solar Cells. Macromolecules 2012, 45, 6587-6599.

27. He, X.; Collins, B. A.; Watts, B.; Ade, H.; McNeill, C. R. Studying Polymer/Fullerene Intermixing and Miscibility in Laterally Patterned Films with X-RaySpectromicroscopy. Small 2012, 12, 1920-1927.

28. Jamieson, F. C.; Domingo, E. B.; McCarthy-Ward, T.; Heeney, M.; Stingelin, N.; Durrant, J. R. Fullerene crystallisation as a key driver of charge separation in polymer/fullerene bulk heterojunction solar cells. Chem. Sci. 2012, 3, 485-492.

29. Schmidt-Hansberg, B.; Sanyal, M.; Klein, M.; Pfaff, M.; Schnabel, N.; Jaiser, S.; Vorobiev, A.; Muller, E.; Colsmann, A.; Scharfer, P. et al. Moving through the Phase Diagram: Morphology 
Formation in Solution Cast Polymer-Fullerene Blend Films for Organic Solar Cells. ACS Nano 2011, 5, 8579-8590.

30. Hopkinson, P. E.; Staniec, P. A.; Pearson, A. J.; Dunbar, A. D. F.; Wang, T.; Ryan, A. J.; Jones, R. A. L.; Lidzey, D. G.; Donald, A. M. A Phase Diagram of the P3HT:PCBM Organic Photovoltaic System: Implications for Device Processing and Performance. Macromolecules 2011, 44, 2908-2917.

31. Shin, M.; Park, H. K. J.; Nam, S.; Heo, K.; Ree, M.; Ha, C.-S.; Kim, Y. Abrupt Morphology Change upon Thermal Annealing in Poly(3-Hexylthiophene)/Soluble Fullerene Blend Films for Polymer Solar Cells. Adv. Func. Mater. 2010, 20, 748-754.

32. Xue, B.; Vaughan, B.; Poh, C.-H.; Burke, K. B.; Thomsen, L.; Stapleton, A.; Zhou, X.; Bryant, G. W.; Belcher, W.; Dastoor, P. C. Vertical Stratification and Interfacial Structure in P3HT : PCBM Organic Solar Cells. J. Phys. Chem C 2010, 114, 15797-15805.

33. Pee, J.; Soci, C.; Coffin, R. C.; Nguyen, T. Q.; Mikhailovsky, A.; Moses, D.; Bazan, G. C. Method for increasing the photoconductive response in conjugated polymer/fullerene composites. Appl. Phys. Lett. 2006, 89, 252105.

34. Su, C.-Y., Ming-Shin Kuo; Yuan, M.-C.; Jeng, U.-S.; Su, C.-J.; Wei, K.-H. Improving Device Efficiency of Polymer/Fullerene Bulk Heterojunction Solar Cells Through Enhanced Crystallinity and Reduced Grain Boundaries Induced by Solvent Additives. Adv. Mater. 2011, 23, 3315-3319.

35. Liu, X.; Hüttner, S.; Rong, Z.; Sommer, M.; Friend, R. H. Solvent additive control of morphology and crystallization in semiconducting polymer blends. Adv. Mater. 2012, 24, 669-674.

36. Walheim, S.; Böltau, M.; Mlynek, J.; Krausch, G.; Steiner, U. Structure Formation via polymer Demixing in Spin-Cast Films. Macromolecules 1997, 30, 4995-5003. 
37. Agostinelli, T.; Lilliu, S.; Labram, J. G.; Campoy-Quiles, M.; Hampton, M.; Pires, E.; Rawle, J.; Bikondoa, O.; Bradley, D. D. C.; Anthopoulos, T. D. et al. Real-Time Investigation of Crystallization and Phase-Segregation Dynamics in P3HT:PCBM Solar Cells During Thermal Annealing. Adv. Func. Mater. 2011, 21, 1701-1708.

38. Kohn, P.; Hüttner, S.; Komber, H.; Senkovskyy, V.; Tkachov, R.; Kiriy, A.; Friend, R. H.; Steiner, U.; Huck, W. T. S.; Sommer, J.-U. et al. On the Role of Single Regiodefects and Polydispersity in Regioregular Poly(3-hexylthiophene): Defect Distribution, Synthesis of DefectFree Chains, and a Simple Model for the Determination of Crystallinity. J. Am. Chem Soc. 2012, 134, 4790-4805.

39. Strobl, G. The physics of polymers; Springer-Verlag: Berlin Heidelberg, 2007.

40. Kiel, J. W.; Kirby, B. J.; Majkrzak, C. F.; Maranvillec, B. B.; Mackay, M. E. Nanoparticle concentration profile in polymer-based solar cells. Soft Matter 2010, 6, 641-646.

41. Geens, W.; Martens, T.; Poortmans, J.; Aernouts, T.; Manca, J.; Lutsen, L.; Heremans, P.; Borghs, S.; Mertens, R.; Vanderzande, D. Thin Solid Films 2004, 451-452, 498-502.

42. Clark, J.; Silva, C.; Friend, R. H.; Spano, F. C. Phys. Rev. Lett. 2007, 98.

43. Pascui, O. F.; Lohwasser, R.; Sommer, M.; Thelakkat, M.; Thurn-Albrecht, T.; Saalwächter, K. High Crystallinity and Nature of Crystal-Crystal Phase Transformations in Regioregular Poly(3-hexylthiophene). Macromolecules 2010, 43, 9401-9410.

44. Malik, S.; Nandi, A. K. Crystallization Mechanism of Regioregular Poly(3-alkyl thiophene)s. J. Polym. Sci. B-Polym. Phys. 2002, 40, 2073-2085.

45. Kozub, D. R.; Vakhshouri, K.; Orme, L. M.; Wang, C.; Hexemer, A.; Gomez, E. D. Polymer Crystallization of Partially Miscible Polythiophene/Fullerene Mixtures Controls Morphology. Macromolecules 2011, 44, 5722-5726. 
46. Busch, P.; Rauscher, M.; Smilgies, D.-M.; Posselt, D.; Papadakis, C. Grazing-incidence smallangle X-ray scattering from thin polymer films with lamellar structures. Appl. Crystallogr. 2006, 36, 433 .

47. Troshin, P. A.; Hoppe, H.; Renz, J.; Egginger, M.; Moyarove, J. Y.; Goryachev, A. E.; Peregudov, A. S.; Lyubovskaya, R. N.; Gobsch, G.; Sariciftci, N. S. et al. Material Solubility- Photovoltaic Performance Relationship in the Design of Novel Fullerene Derivatives for Bulk Heterojunction Solar Cells. Adv. Funct. Mater. 2009, 19, 779-788.

48. Roth, S.; Döhrmann, R.; Dommach, M.; Kuhlmann, M.; Kröger, I.; Gehrke, R.; Walter, H.; Schroer, C.; Lengeler, B.; Müller-Buschbaum, P. The small-angle options of the upgraded USAXS beamline BW4 at HASYLAB. Rev. Sci. Instr. 2006, 77, 085106.

49. Buffet, A.; Rothkirch, A.; Döhrmann, R.; Körstgens, V.; Kashem, M. M. A.; Perlich, J.; Herzog, G.; Schwartzkopf, M.; Gehrke, R.; Müller-Buschbaum, P. et al. P03, the microfocus and nanofocus X-ray scattering (MiNaXS) beamline of the PETRA III storage ring: the microfocus endstation. J. Synchrotron Rad. 2012, 19, 647-653.

50. Tashiro, K.; Kobayashi, M.; Kawai, T.; Yoshino, K. Crystal structural change in poly(3-alkyl thiophene)s induced by iodine doping as studied by an organized combination of x-ray diffraction, infrared/Raman spectroscopy and computer simulation techniques. Polymer 1997, 38, 2867-2879. 